\title{
Bisecting real and fake body parts: effects of prism adaptation after right brain damage
}

\author{
Nadia Bolognini ${ }^{1,2}{ }^{*}$, Debora Casanova ${ }^{1}$, Angelo Maravita ${ }^{1}$ and Giuseppe Vallar ${ }^{1,2}$ * \\ ${ }^{1}$ Department of Psychology, University of Milano-Bicocca, Milan, Italy \\ ${ }^{2}$ Neuropsychological Laboratory, IRCCS Italian Institute for Auxology, Milan, Italy
}

\author{
Edited by: \\ Konstantinos Priftis, University of \\ Padova, Italy
}

\section{Reviewed by:}

Lorenzo Pia, University of Turin, Italy Margarita Sarri, University College London, UK

\section{*Correspondence:}

Nadia Bolognini and Giuseppe Vallar, Dipartimento di Psicologia, Università degli Studi di Milano-Bicocca, Piazza dell'Ateneo Nuovo, 1, 20126 Milano, Italy.

e-mail: nadia.bolognini@unimib.it, giuseppe.vallar@unimib.it
The representation of body parts holds a special status in the brain, due to their prototypical shape and the contribution of multisensory (visual and somatosensory-proprioceptive) information. In a previous study (Sposito et al., 2010), we showed that patients with left unilateral spatial neglect exhibit a rightward bias in setting the midpoint of their left forearm, which becomes larger when bisecting a cylindrical object comparable in size. This body part advantage, found also in control participants, suggests partly different processes for computing the extent of body parts and objects. In this study we tested 16 right-brain-damaged patients, and 10 unimpaired participants, on a manual bisection task of their own (real) left forearm, or a size-matched fake forearm. We then explored the effects of adaptation to rightward displacing prism exposure, which brings about leftward aftereffects. We found that all participants showed prism adaptation (PA) and aftereffects, with right-brain-damaged patients exhibiting a reduction of the rightward bias for both real and fake forearm, with no overall differences between them. Second, correlation analyses highlighted the role of visual and proprioceptive information for the metrics of body parts. Third, single-patient analyses showed dissociations between real and fake forearm bisections, and the effects of PA, as well as a more frequent impairment with fake body parts. In sum, the rightward bias shown by right-brain-damaged patients in bisecting body parts is reduced by prism exposure, as other components of the neglect syndrome; discrete spatial representations for real and fake body parts, for which visual and proprioceptive codes play different roles, are likely to exist. Multisensory information seems to render self bodily segments more resistant to the disruption brought about by right-hemisphere injury.

Keywords: prismatic adaptation, space coding, body representation, multisensory, unilateral spatial neglect

\section{INTRODUCTION}

After an unilateral brain damage patients may show an altered representation of the space contralateral to the damaged hemisphere, that produces the neuropsychological syndrome of unilateral spatial neglect (USN). USN is more frequent and severe after damage to the right cerebral hemisphere, and involves the left portion of egocentric space in right-handed patients (Vallar, 1998; Bisiach and Vallar, 2000; Heilman et al., 2003; Husain, 2008; Vallar and Bolognini, in press). Basically, patients with USN show an inability to report sensory events occurring in the left side of space, contralateral to the side of the lesion (contralesional), and to perform actions in that portion of space. The deficit is dissociated from primary sensory and motor disorders, may be modality-specific, and conscious awareness may be more or less completely lost for the contralesional side of space. Patients with USN may show a variety of selective patterns of impairment, suggesting the existence of multiple spatial representations for different sectors of physical and imaginal space (Vallar and Bolognini, in press), and for specific stimuli, such as letter strings (Vallar et al., 2010). Particularly, USN may concern near extra-personal space or the body (Bisiach et al., 1986a; Guariglia and Antonucci, 1992; Committeri et al., 2007; Vallar and Maravita, 2009). These dissociations suggest that the internal representation of the space around us, far from being unitary, includes a number of discrete, though related, components, with partly different neural correlates (Rizzolatti et al., 1997; Vallar, 1998).

One hallmark of the syndrome of left USN is a rightward deviation error in the task of bisecting a horizontal line (Schenkenberg et al., 1980; Bisiach et al., 1983; Vallar et al., 2000; but see Karnath and Rorden, 2012, for the view that a line bisection bias is not a core manifestation of USN). The line bisection task is a standard, simple test, widely used for the clinical diagnosis and the experimental investigation of USN. This task has been typically employed to explore the spatial representation, particularly the lateral extent, of extra-personal objects, most frequently segments (Schenkenberg et al., 1980; Bisiach et al., 1983; Halligan and Marshall, 1994; Vallar et al., 2000). Recently, we used this task to explore the spatial metrics of body parts in rightbrain-damaged patients with left USN, and in neurologically unimpaired participants (Sposito et al., 2010). Particularly, we demonstrated that USN patients show a rightward bisection bias for both their own left forearm and a three-dimensional extracorporeal object comparable in size (i.e., a plastic cylinder), as compared to control participants. However, analyses of group 
performance showed that the bisection error is minor for the forearm, in both USN patients (with a reduction of the rightward bias), and in neurologically unimpaired participants. Yet, single-patient analyses also reveal that in USN patients the rightward bias can be significantly more severe either in cylinder than in forearm bisection (the prevailing pattern, as indicated by the above mentioned group analysis), or, vice versa, in forearm bisection. This double dissociation suggests the existence of independent representations for extra-personal objects and body parts, likely supported by discrete spatial processes (Sposito et al., 2010).

In the same study we also performed a second experiment in neurologically unimpaired participants, investigating the mechanisms underlying the body part (forearm) advantage, using a fake forearm as the object, instead of the cylinder. No advantage for the real, as compared to the fake, forearm was found in the bisection task, suggesting that real and fake body parts share a common spatial representation, primarily based on a visuo-spatial code (Sposito et al., 2010).

The present study further explored the spatial representation of real and fake body parts in right-brain-damaged patients, with and without USN, and in neurologically unimpaired participants. The aim was twofold. First, we looked for putative differences in real vs. fake forearm bisection biases in right-brain-damaged patients, to explore the hypothesis (Sposito et al., 2010) that the involved representation is based upon a visuo-spatial coding of the metrics of body parts, with therefore no differences between real and fake forearm bisections. Second, we assessed the effects of prism adaptation (PA) on the bisection of (real and fake) body parts. Basically, PA consists in a short period of adaptive pointing toward targets optically displaced by prisms (Redding et al., 2005). As far as left USN is concerned, patients' exposure to prisms displacing the visual scene rightward, after adaptation through a visuo-spatial pointing task, brings about a leftward displacement in pointing ("aftereffects," occurring subsequent to prism removal), and an improvement of many manifestations of USN (Redding et al., 2005; Rode et al., 2006a). The mechanisms whereby PA operates are complex and debated (Rossetti et al., 1999; Redding et al., 2005). In USN patients adaptation to rightward displacing prisms may operate by restoring the egocentric reference frame, pathologically distorted rightward, and bringing previously neglected space into awareness. The manifestations of USN temporarily alleviated by PA include visual (Rossetti et al., 1998; Farnè et al., 2002; Vallar et al., 2006), haptic/somatosensory (McIntosh et al., 2002; Maravita et al., 2003a), auditory (Jacquin-Courtois et al., 2010), and representational (Rode and Perenin, 1994; Rossetti et al., 2004) deficits. We predicted that if real and fake body parts share a similar visuo-spatial representation, PA is expected to modulate their bisection bias in a similar way.

\section{MATERIALS AND METHODS PARTICIPANTS}

Participants were recruited from the inpatient population of the IRCCS Istituto Auxologico Italiano (Milano, Italy). All participants gave their informed consent to participate in the study. The protocol was carried out in accordance with the ethical standards of the Declaration of Helsinki (BMJ 1991; 302: 1194), and it was approved by the ethical committee of the IRCCS Istituto Auxologico Italiano.

Participants in the study included: 10 right-handed healthy subjects (i.e., Control Group, four males and six females; mean age: 56, range: $36-83$; educational level: 9 , range: $5-13$ ), with no history or evidence of neurological disease; 16 right-handed righthemisphere-damaged patients (i.e., RHD Group, 5 males and 11 females; mean age: 60, range: 30-97; educational level: 12 , range: 5-19). For the patients' groups, inclusion criteria were the presence of a right hemispheric lesion. All patients had no evidence of previous neurological disease or psychiatric disorders.

Contralesional motor, somatosensory, and visual field deficits, including extinction to tactile and visual stimuli, were assessed by a standard neurological examination; for each function tested (i.e., visual, somatosensory, and motor), the score range was: $3=$ maximum deficit; $0=$ unimpaired performance (Bisiach and Faglioni, 1974). Anosognosia for neurological deficits was assessed by the standard interview of Bisiach et al. (1986b), which provides scores ranging from 0 (no anosognosia) to 3 (maximum deficit).

Position sense disorders were assessed by using the test developed by Vallar et al. (1993). The patient's contralesional (left) forearm was placed on the bottom of a black box, which prevented patients from viewing the tested forearm. The upper limb was placed extended on a table, and the forearm was moved passively by the examiner to four different positions: straight ahead, $30^{\circ}, 60^{\circ}$, and $90^{\circ}$ adducted, with respect to the arm, toward the patient's trunk. In each trial, the starting point was a position with the forearm straight ahead; the forearm was repeatedly adducted and abducted before the intended position was reached. Patients received instructions to look in front of them while the examiner moved their arm to the intended position, and to communicate the perceived position of the arm, by pointing to the corresponding silhouette on the cover of the box. There were 40 trials (10 per position), in a random-fixed order. The score was the number of errors, i.e., a reported position of the forearm different from the actual position (error range: $0-40$ ). The control participants' average error was 0.087 (range 0-2; Vallar et al., 1993).

The demographical and clinical details of each patient are reported in Table 1.

\section{BASELINE NEUROPSYCHOLOGICAL ASSESSMENT FOR EXTRA-PERSONAL AND PERSONAL USN Cancelation tasks: letter, bell, star}

In the Letter task (Diller and Weinberg, 1977) the score was the number of " $\mathrm{H}$ " letter targets crossed out by each participant ( 53 on the left-hand side and 51 on the right-hand side of the sheet). Neurologically unimpaired participants made a mean of $0.13(0.12 \%$, $\mathrm{SD} \pm 0.45$, range $0-4)$ omission errors out of 104 targets, with the maximum difference between omissions on the two sides of the sheet being two targets (Vallar et al., 1994). In the Bell task (Gauthier et al., 1989), the score was the number of "bell" targets crossed out by each participant (18 on the left-hand side, and 17 on the right-hand side of the sheet). Neurologically unimpaired participants made a mean of $0.47(1.3 \%, \mathrm{SD} \pm 0.83$, range $0-4)$ omission errors out of 35 targets, with the maximum difference between omissions on the two sides of the sheet being four targets (Vallar et al., 1994). In the Star task (Wilson et al., 1987) the score 
Table 1 | Demographical and neurological data.

\begin{tabular}{|c|c|c|c|c|c|c|c|c|c|c|c|}
\hline & & \multirow[t]{2}{*}{$\begin{array}{l}\text { Length of } \\
\text { illness (days) }\end{array}$} & \multirow[t]{2}{*}{ Etiology } & \multirow[t]{2}{*}{ Age/gender } & \multicolumn{3}{|c|}{$\begin{array}{l}\text { Neurological } \\
\text { examination }\end{array}$} & \multicolumn{3}{|c|}{ Anosognosia } & \multirow[t]{2}{*}{ Position sense } \\
\hline & & & & & $\mathbf{v}$ & ss & M & $\mathbf{v}$ & ss & $\mathbf{M}$ & \\
\hline $\mathrm{N}-$ & P1 & 17 & $\mathrm{~T}+\mathrm{H}$ & $41 / F$ & - & - & + & - & - & - & 0 \\
\hline $\mathrm{N}-$ & P2 & 15 & $\mathrm{~T}$ & $55 / \mathrm{M}$ & - & - & - & - & - & - & 1 \\
\hline $\mathrm{N}-$ & P3 & 58 & $\mathrm{~A}+\mathrm{H}$ & $63 / F$ & NA & NA & NA & NA & NA & NA & 0 \\
\hline $\mathrm{N}-$ & P5 & 38 & I & $52 / F$ & - & - & + & - & - & - & NA \\
\hline $\mathrm{N}-$ & P6 & 33 & 1 & $53 / \mathrm{M}$ & - & $E$ & + & - & - & - & 3 \\
\hline $\mathrm{N}-$ & P7 & 30 & 1 & $66 / F$ & - & $E$ & + & - & - & - & 0 \\
\hline $\mathrm{N}-$ & P8 & 32 & 1 & $78 / F$ & $E$ & ++ & ++ & - & + & + & 7 \\
\hline $\mathrm{N}-$ & P9 & 17 & $\mathrm{H}$ & $57 / F$ & - & $E$ & ++ & - & - & - & 6 \\
\hline $\mathrm{N}+$ & P10 & 47 & $\mathrm{I}+\mathrm{H}$ & $97 / F$ & ++ & + & ++ & ++ & ++ & ++ & NA \\
\hline $\mathrm{N}+$ & P14 & 547 & $\mathrm{~T}$ & $30 / \mathrm{M}$ & ++ & ++ & ++ & - & - & - & 12 \\
\hline $\mathrm{N}+$ & P15 & 40 & $\mathrm{H}+\mathrm{T}$ & $70 / F$ & ++ & ++ & ++ & + & + & - & NA \\
\hline $\mathrm{N}+$ & P16 & 23 & TBI & $60 / \mathrm{M}$ & ++ & ++ & ++ & - & - & - & 19 \\
\hline
\end{tabular}

Etiology: I/H/A/T/TBI, ischemic/hemorrhagic/aneurysm/tumor/traumatic brain injury. Neurological examination: M/SSN, motor/somatosensory/visual half-field deficits contralateral to the damaged hemisphere. Anosognosia: M/SSN, for motor/somatosensory/visual half-field deficits. e, extinction to double simultaneous stimulation (for visual and somatosensory deficits); ++/4, severe/moderate deficit; -, no deficit; NA, not available. Position sense: $n^{\circ}$ errors out of 40 trials. $N-$, patients without USN; N+, patients with USN.

was the number of small "star" targets crossed out by each participant (30 on the left-hand side and 26 on the right-hand side). Ten neurologically unimpaired participants (mean age: 72.2, SD: 5.27, range: 67-82; mean years of schooling 9.2, SD: 6.21, range: $3-18)$ scored 0.5 average omissions $(0.9 \%, \mathrm{SD}: \pm 0.7$, range: $0-2)$, with the maximum difference between omission errors on the two sides of the sheet being one target (Fortis et al., 2010).

\section{Line bisection}

The patients' task was to mark with a pencil the midpoint of six horizontal black lines (two $10 \mathrm{~cm}$, two $15 \mathrm{~cm}$, and two $25 \mathrm{~cm}$ in length, all $2 \mathrm{~mm}$ in width), presented in a random-fixed order. Each line was printed in the center of an A4 sheet, aligned with the midsagittal plane of the participant's body. The length of the left-hand side of the line (i.e., from the left end of the line to the participant's mark) was measured to the nearest millimeter. A deviation score (percentage deviation) was then computed by means of the following formula: measured left half minus objective left half)/objective left half $\times 100$ (Rode et al., 2006b; Sposito et al., 2010). This transformation yields positive numbers for rightward deviations, and negative numbers for leftward deviations. Control data for this version of the line bisection test were available from 65 neurologically unimpaired participants (mean age: 72.2 , range: 65-83; educational level: 9.5, range: 5-18). The mean percentage of bisection error of the control group was $-1.21 \%$ ( $\mathrm{SD} \pm 3.48$, range: -16.2 to $+6.2 \%$; Fortis et al., 2010).

Five-element complex drawing (Gainotti et al., 1972)

The patients' task was to copy a complex five-element figure: from left to right, two trees, a house, and two pine trees. Each element was scored 2 (flawless copy), 1.5 (partial omission of the lefthand side of an element), 1 (complete omission of the left-hand side of an element), 0.5 (complete omission of the left-hand side of an element, together with partial omission of the right-hand side of the same element), or 0 (no drawing, or no recognizable element). The total score ranged from 0 to 10 . According to normative data from 148 neurologically unimpaired participants (age: range 40-79; education: range 5-13 years of schooling) a score lower than 10 indicated a defective performance (Fortis et al., 2010).

\section{Sentence reading (Pizzamiglio et al., 1992)}

Patients were asked to read six sentences. The score was the number of correctly read sentences (range 0-6). Ten control participants (see above, star cancelation) made no neglect-like errors, and 0.3 ( $5 \%, \mathrm{SD} \pm 0.64$, range $0-2$ ) other errors (Fortis et al., 2010).

\section{Personal neglect test (Fortis et al., 2010)}

In this test patients were asked to reach six left-sided body parts (ear, shoulder, elbow, wrist, waist, knee), using their right hand. Each response was scored 0 (no movement), 1 (search without reaching), 2 (reaching with hesitation and search), or 3 (immediate reaching), with a $0-18$ score range. Ten control participants (see above, star cancelation) made no errors (Fortis et al., 2010).

The patients' performance in each test is reported in Table 2. A pathological score in at least three tests was considered as an index of USN (see Fortis et al., 2010, for such a criterion); using this criterion, 7 out of 16 RHD patients showed USN (i.e., from patient $\mathrm{P} 10$ to patient $\mathrm{P} 16$ ). 
Table 2 | Assessment for visuo-spatial neglect.

\begin{tabular}{|c|c|c|c|c|c|c|c|c|c|c|}
\hline & \multirow{2}{*}{$\begin{array}{l}\text { Line } \\
\text { bisection (\%) }\end{array}$} & \multicolumn{2}{|c|}{ Bell cancelation } & \multicolumn{2}{|c|}{ Letter cancelation } & \multicolumn{2}{|c|}{ tar cancelation } & \multirow{2}{*}{$\begin{array}{l}\text { Drawing } \\
\text { (out of 10) }\end{array}$} & \multirow{2}{*}{$\begin{array}{l}\text { Reading } \\
\text { (out of } 6 \text { ) }\end{array}$} & \multirow{2}{*}{$\begin{array}{l}\text { Personal neglect } \\
\text { (out of 18) }\end{array}$} \\
\hline & & $\begin{array}{l}L \\
\text { (out of 18) }\end{array}$ & $\begin{array}{l}\text { R } \\
\text { (out of 17) }\end{array}$ & $\begin{array}{l}\text { L } \\
\text { (out 53) }\end{array}$ & $\begin{array}{l}\text { R } \\
\text { (out of 51) }\end{array}$ & $\begin{array}{l}L \\
\text { (out of } 30 \text { ) }\end{array}$ & $\begin{array}{l}\text { R } \\
\text { (out of 26) }\end{array}$ & & & \\
\hline P1 & -1 & 1 & 3 & 1 & 0 & 0 & 0 & 10 & 6 & 18 \\
\hline P2 & -9 & 1 & 0 & 0 & 0 & NA & NA & 10 & NA & 18 \\
\hline P3 & -3.4 & 1 & 0 & NA & NA & NA & NA & 10 & 6 & 18 \\
\hline P4 & 2.2 & 1 & 0 & 0 & 0 & 0 & 0 & 10 & 6 & 18 \\
\hline P5 & -4.2 & 1 & 1 & 0 & 0 & 0 & 0 & 10 & 6 & 18 \\
\hline P6 & -2 & 4 & 0 & 2 & 3 & 0 & 0 & 10 & 6 & NA \\
\hline P7 & +5.2 & 4 & 0 & 0 & 3 & 1 & 0 & 10 & 6 & 18 \\
\hline P8 & -3 & 2 & 4 & 2 & 4 & 0 & 2 & $9.5^{*}$ & 6 & 18 \\
\hline P9 & -0.2 & 0 & 0 & 0 & 0 & 0 & 0 & $9.5^{*}$ & 6 & 18 \\
\hline P10 & $+24.6^{*}$ & $18^{*}$ & $16^{*}$ & $53 *$ & $49 *$ & $30 *$ & $19 *$ & $1^{*}$ & $0^{*}$ & $16^{*}$ \\
\hline P11 & $+9^{*}$ & 2 & 1 & $19 *$ & $12 *$ & $15^{*}$ & $0^{*}$ & 10 & 6 & $17^{*}$ \\
\hline P12 & $+6.2^{*}$ & 1 & 0 & $50 *$ & $8^{*}$ & $11 *$ & $0^{*}$ & $9 *$ & 6 & $17^{*}$ \\
\hline P13 & $+77.8^{*}$ & $18 *$ & $3^{*}$ & $53 *$ & $35^{*}$ & $30 *$ & $15^{*}$ & $4^{*}$ & $0^{*}$ & 18 \\
\hline P14 & $+16^{*}$ & $18 *$ & $8^{*}$ & $20^{*}$ & $0^{*}$ & $30 *$ & $7^{*}$ & 10 & $3^{*}$ & 18 \\
\hline P15 & $+83.2^{*}$ & $18 *$ & $13^{*}$ & $53 *$ & $47^{*}$ & $30 *$ & $18^{*}$ & $2^{*}$ & $0^{*}$ & $14^{*}$ \\
\hline P16 & $+70^{*}$ & $18^{*}$ & $12^{*}$ & $53 *$ & $40^{*}$ & $30 *$ & $18 *$ & $1.5^{*}$ & $0^{*}$ & $16 *$ \\
\hline
\end{tabular}

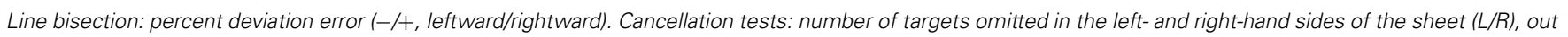

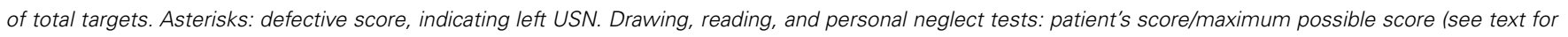
details). NA, not available.

\section{LESION DATA}

Figure 1 shows the mapping of the brain lesions for the 14 out of the 16 RHD patients, for whom the original brain scan was available. Lesions were mapped using the software MRIcro (Rorden and Brett, 2000). We reconstructed the region of interest (ROI) to define the location and the size of the lesion for each patient by using a Template Technique, that is, by manually drawing the lesion on the standard template from the Montreal Neurological Institute. ROIs were created by mapping the regions on each and every $2 \mathrm{D}$ slice of a $3 \mathrm{D}$ volume.

\section{EXPERIMENTAL PROCEDURE \\ Body bisection task}

Participants sat on a chair and were presented with a stimulus in front of them which could be either their own left forearm (real forearm condition) or a left fake forearm (fake forearm condition), placed at a distance of about $20 \mathrm{~cm}$ from the participant, with the objective midpoint aligned with their midsagittal plane. The fake forearm was a realistic, custom-made reproduction of a human male or female arm made by a scenic studio, and its length was broadly matched to that of a real forearm, as measured between the proximal and distal extremities of the ulnar bone (real forearm, controls $=23.6 \mathrm{~cm} \pm 1.9$; Patients $=23 \mathrm{~cm} \pm 1.9$; fake fore$\operatorname{arm}=24 / 22 \mathrm{~cm}$, for a male/female forearm, respectively). During the bisection tasks, patients wore a black mantle; in the real forearm condition, each participant slid off the forearm from two side holes made in the mantle, so that only the forearm remained visible, while the hand and the arm above the elbow remained covered by the mantle; in the same way, in the fake forearm condition, only the fake forearm was out of the mantle (see Figure 2A). In both conditions, the right and the left extremities of the forearm were marked by black tags, and were clearly indicated to each participant prior to each block of trials.

Participants rested their right index finger touching their body midline at the level of the sternum. In each trial, they were required to point with their right index finger to the perceived midpoint of each stimulus, considering the black tags as its right and left endpoints. Each pointing was performed once, with no time constraints and no corrections allowed. After each trial, the distance between the left side of the stimulus and the participant's pointing was measured to the nearest millimeter. The participant was then required to put the index finger back to the starting position, before the following trial. The bisection task, comprising both real and fake forearm conditions, was given to participants in two sessions, namely before and after a 10 -min application of $10^{\circ}$ right-shifting prismatic lenses during pointing (see below, PA). Stimulus condition was blocked in an ABAB (BABA) design, with each block comprising 12 trials for each stimulus condition (i.e., two blocks were administered before PA, and two blocks after PA). In sum, there were a total of 48 trials, 24 for each stimulus condition (i.e., 24 Real forearm bisections, and 24 Fake forearm bisections), 24 (12 Real, and 12 Fake) before and 24 after PA. The order of the Real and Fake conditions was randomized across participants. A percent deviation score was calculated for both conditions with the formula used for the line bisection test.

\section{Prism adaptation}

The procedure of Frassinetti et al. (2002), and of Fortis et al. (2010) was used. Each participant was seated in front of a table. A wooden box (height $30 \mathrm{~cm}$, depth $34 \mathrm{~cm}$ at the center, and $18 \mathrm{~cm}$ at the two 

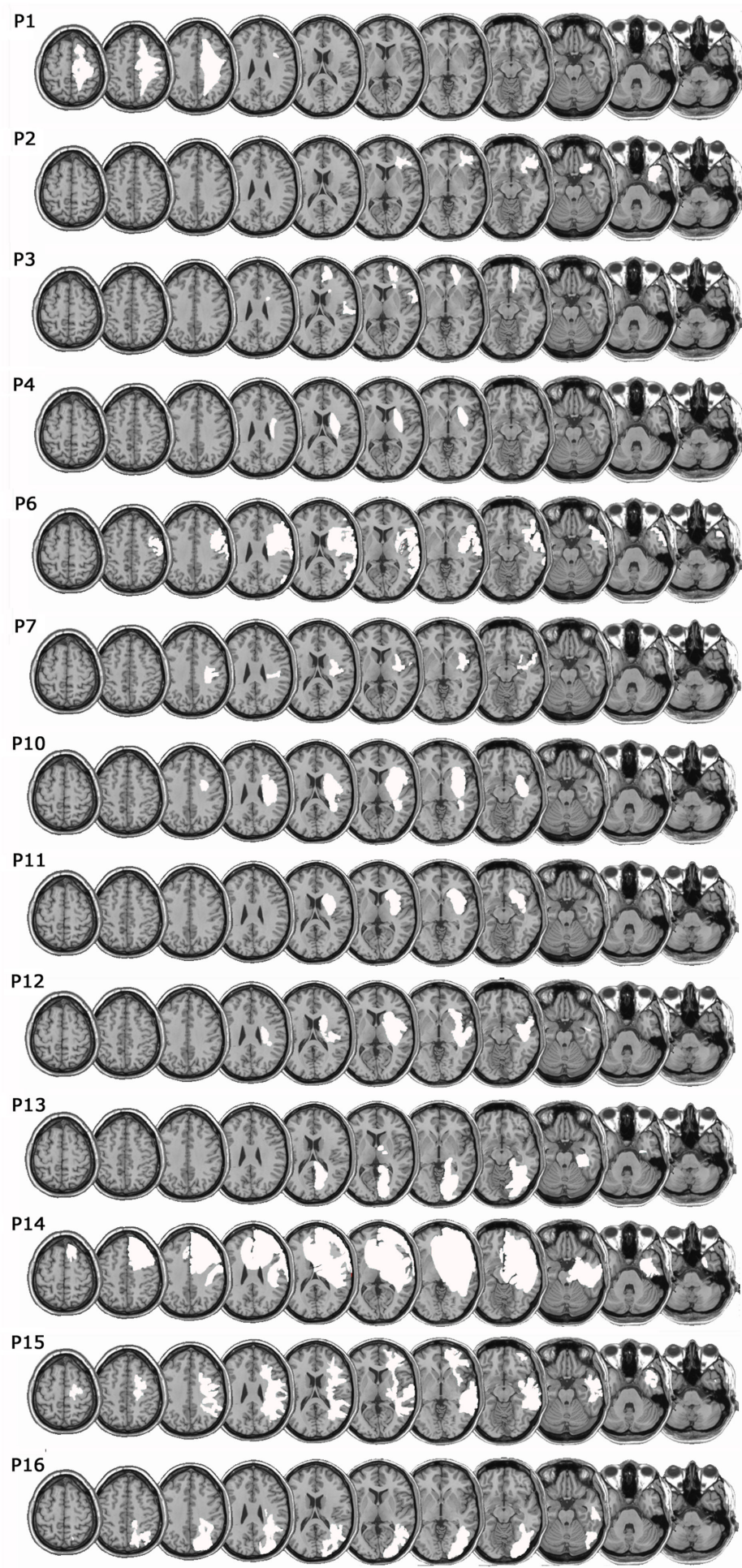

FIGURE 1 | Lesion mapping. Lesions were mapped onto a standard template (Montreal Neurological Institute) using the software MRIcro (Rorden and Brett, 2000). White areas represent the extension of the lesion of each patient.

sides, width $72 \mathrm{~cm}$ ) was placed in front of him or her. The box was open on the side facing the participant ("proximal"), and on the opposite side ("distal"), facing the experimenter. On the experimenter's side (distal), the box could be made either open ("visible pointing"), or closed by a removable plexiglas ("invisible pointing" condition). In the visible pointing condition, the 


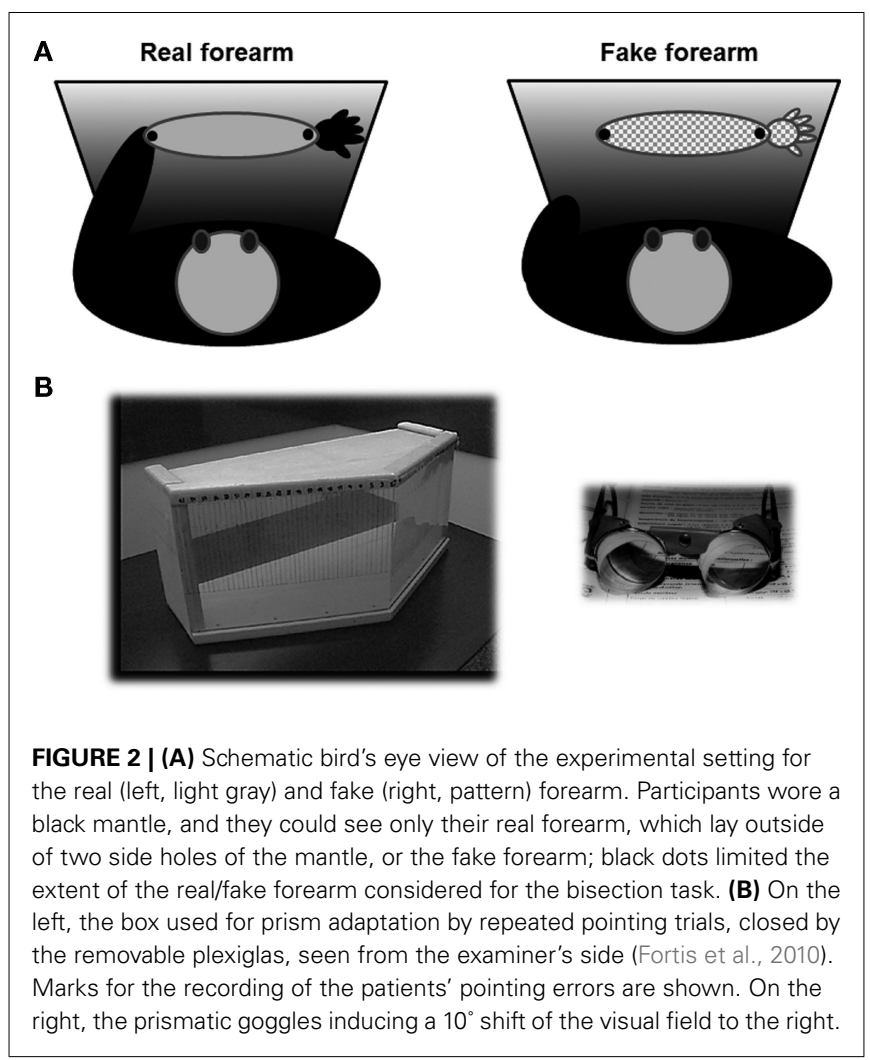

participant's index finger came out of the box's open distal side, becoming visible to the participant. A visual target (a pen) was presented manually by the experimenter at the distal edge of the top face of the box (see Figure 2B). The visual target was presented randomly in one of three possible positions: central, straight ahead in front of the participant $\left(0^{\circ}\right)$, lateral to the left $\left(-21^{\circ}\right)$ or to the right $\left(+21^{\circ}\right)$ of the participant's body midline. The distal edge of the top face of the box was graduated (in degrees), so that the experimenter measured the patients' pointing accuracy, namely the distance between their finger and the target, measured in degrees. A positive score denoted a rightward displacement with respect to the position of the target, a negative score a leftward displacement.

Participants were asked to keep their right hand, ipsilateral to the side of the lesion (ipsilesional) for right-brain-damaged patients, on their chest, at the level of the sternum (hand starting position) and to point with their right index finger toward the pen, at a fast but comfortable speed. The movement of the participant's pointing arm was executed below the top face of the wooden box, so that they could not see the arm's trajectory. Once the experimenter had recorded the patient's pointing performance, the patient retrieved the arm and prepared for the successive trial. The pointing task was performed in three experimental conditions: Pre-exposure, Exposure, and Post-exposure.

Pre-exposure condition. In this condition, immediately before wearing the prismatic goggles, participants were required to point with their index finger toward 60 targets presented randomly in one of the above mentioned three possible positions (20 targets at the center, 20 at $-21^{\circ}$ and 20 at $+21^{\circ}$ ). Participants performed the first block of trials (30) with visible pointing, and the second block with invisible pointing.

Exposure condition. Participants wore prismatic goggles (Optique Peter, Lyon, France), fitted with wide-field, prismatic lenses, inducing a $10^{\circ}$ shift of the visual field to the right. Participants were asked to point with their right index finger to 90 targets presented in a random-fixed order in each of the three possible positions (30 targets at the center, 30 at $-21^{\circ}$, and 30 at $+21^{\circ}$ ). The pointing movement was hidden below the top face of the box, apart from its final part, where the index finger emerged beyond the distal edge of the top face of the box (visible pointing).

Post-exposure condition. Immediately after prism removal, participants were required to point to 30 targets (10 targets at the center, 10 at $-21^{\circ}$, and 10 at $+21^{\circ}$ ) in a random-fixed order. As in the pre-exposure condition, pointing was invisible.

\section{STATISTICAL ANALYSES}

To assess the presence and amount of the aftereffects following $\mathrm{PA}$, we compared the participants' pointing error in the preexposure and post-exposure conditions by a repeated-measures analysis of variance (ANOVA) with Group as a between-subjects factor (Control, RHD), and two within-subjects factors: Session (pre-exposure, post-exposure), and Target position (left, center, and right). The dependent measure in this analysis was the mean displacement (expressed as degrees of visual angle) of the participants' invisible pointing responses.

We also analyzed the visible pointing responses in the preexposure condition via a repeated-measures ANOVA with Group as a between-subjects factor, and Target Location as a withinsubjects factor.

Second, we assessed the effect of PA on the participants' performance in the body bisection task; the mean percentage of deviation errors was analyzed by a repeated-measures ANOVA with Group (Control, RHD) as a between-subjects factor, and two withinsubjects factors: Stimulus (real forearm and fake forearm), and Session (pre-exposure and post-exposure).

Moreover, in order to control for a possible effect of the lesion size in determining the body bisection pattern and the PA effect in RHD patients, we carried out an analysis of covariance (ANCOVA) on the RHD patients' mean bisection error with Stimulus and Session as within-subjects factor, and Lesion size (mean volume of the lesion $=90 \mathrm{cc}$, range $=40-25 \mathrm{cc}$ ) as covariate (the covariate was mean centered prior to the analyses).

For every analysis, we calculated the partial Eta Squared $\left(p \eta^{2}\right)$, which measures the proportion of the total variance that is attributable to a main factor or to an interaction (Cohen, 1973), and whenever necessary pairwise comparisons were conducted with the Newman-Keuls test. The level of significance was always set at 0.05 .

To assess for the presence of any significant defective performance in individual RBD patients, we compared the deviation errors in the real and fake forearm conditions (considering the data before PA, i.e., the pre-exposure session) of each patient, with those of healthy participants. The comparison was performed by $t$-tests 
following the procedure of Crawford and Garthwaite (2005). Following the same procedure, we also compared the effects of PA on real and fake forearm bisections (i.e., the difference between the percent scores in the pre-exposure and post-exposure sessions) in each patient, with those of healthy control participants. Furthermore, following the Revised Standardized Difference Test (Crawford and Garthwaite, 2005), we compared in each patient the difference between real and fake forearm bisections in the pre-exposure condition, as well as between the effects of PA in the two bisection conditions, with the same differences in the neurologically healthy participants.

Finally, for right-brain-damaged patients, Pearson's correlation analyses were performed between the bisection error in the real and fake forearm conditions and the following variables: scores in the forearm proprioceptive test, in the standardized neurological exam (visual, tactile, and motor deficits), and in the clinical tests assessing USN.

\section{RESULTS}

\section{AFTEREFFECTS}

As Figure 3A shows, aftereffects (as indexed by the difference between the pointing errors during invisible pointing, before and after PA) took place after prism removal in controls and RHD patients. The ANOVA showed a significant main effect of Session $\left[F(1,24)=37.52 ; P<0.001, p \eta^{2}=0.99\right]$, with a larger leftward deviation (i.e., aftereffects) in the post-exposure $\left(-2.1^{\circ}\right)$, as compared to the pre-exposure session $\left(-0.36^{\circ}\right)$. The main effect of Target location was significant $[F(2,48)=13.39 ; P<$ 0.0001, $\left.p \eta^{2}=0.86\right]$ : invisible pointing deviations to left target stimuli $\left(-0.82^{\circ}\right)$ differed from central $\left(-1.22^{\circ}, P<0.01\right)$ and right $\left(-1.65^{\circ}, P<0.01\right)$ target stimuli; pointing to central and right target stimuli were different too $(P<0.02)$. Other main effects and interactions were not significant: Group $[F(1,24)=0.39$; $\left.P=0.5, p \eta^{2}=0.02\right]$, Group by Session $[F(1,24)=0.26 ; P=0.6$, $\left.p \eta^{2}=0.01\right]$, Group by Target location $[F(2,48)=2.11 ; P=0.1$,
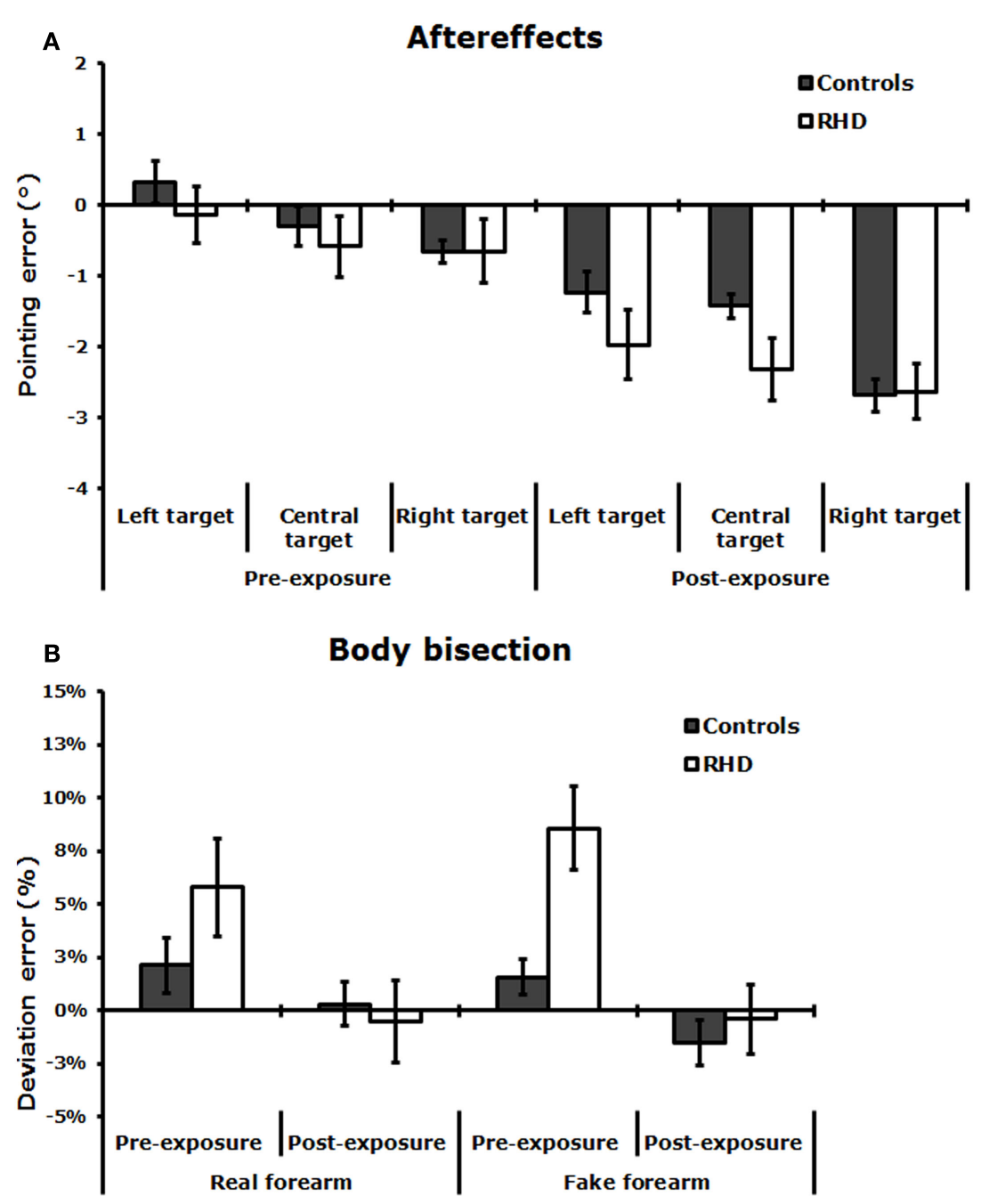

FIGURE 3 | (A) Aftereffects: Invisible condition. Mean pointing error (in degrees of visual angle, $\pm S E$ ) in the pre-exposure and post-exposure sessions, made by neurologically unimpaired control participants, and RHD patients. (B) Mean percent deviation error $( \pm S E)$ made by control participants and $\mathrm{RHD}$ patients, by stimulus condition (real and fake forearm), before and after PA. 
$\left.p \eta^{2}=0.08\right]$, Session by Target location $[F(2,48)=2.29 ; P=0.1$, $\left.p \eta^{2}=0.09\right]$, Group by Session by Target location $[F(2,48)=0.73$; $\left.P=0.5, p \eta^{2}=0.03\right]$. The lack of significant interactions involving the Group main factor indicates that the size of the aftereffects was comparable across the two groups, as well as the pointing deviations to different target locations.

The analysis of visible pointing responses in the preexposure condition showed a significant effect of Target location $\left[F(2,48)=5.02 ; P<0.01, p \eta^{2}=0.2\right]$ : visible pointing deviations to left target stimuli $\left(1.58^{\circ}\right)$ differed from central $\left(1.12^{\circ}, P<0.01\right)$, and right $\left(0.99^{\circ}, P<0.01\right)$ target stimuli; pointings to central and right target stimuli did not differ $(P=0.4)$. Other main effects and interactions were not significant: Group $[F(1,24)=3.12 ; P=0.07$, $\left.p \eta^{2}=0.2\right]$, and Group by Target location $[F(2,48)=0.07 ; P=0.9$, $\left.p \eta^{2}=0.01\right]$. These findings suggest that both controls and RHD patients were equally accurate in pointing to visual targets in a baseline (with no prisms) condition.

\section{EFFECTS OF PRISM ADAPTATION ON BODY BISECTION}

Figure 3B shows that, in the Pre-exposure session, each group made a deviation error toward the right side in both the real and the fake forearm conditions, with a slightly more accurate performance in the real than in the fake forearm condition in RHD patients. RHD patients produced a larger rightward bisection error than neurologically unimpaired control overall. In the Postexposure session, in both stimulus conditions the rightward bias diminished in all groups, with a greater effect emerging in RHD patients. The ANOVA revealed a significant main effect of exposure Session $\left[F(1,24)=21.38 ; P<0.0001, p \eta^{2}=0.47\right]$, showing that both in controls and RHD patients there was a reduction of the rightward error in the estimation of the subjective midpoint of the real and fake forearms in the Post-exposure session $(-0.51 \%$, $P<0.001$ ), as compared to the Pre-exposure session (5.13\%). The significant Group by Session interaction $[F(2,24)=5.67$; $P<0.02, p \eta^{2}=0.37$ ] showed that PA diminished the rightward bias in RHD patients only, in either stimulus condition (preexposure $=+7.19 \%$ vs. post-exposure $=-0.45 \%, P<0.001$ ), with no PA effects in control participants (pre-exposure $=+1.85 \%$ vs. post-exposure $=-0.6 \%, P=0.3)$. RHD patients differed from control participants only in the pre-exposure session $(P<0.05)$, but not in the post-exposure session $(P=0.9)$. The main effect of Group $\left[F(1,24)=1.76 ; P=0.2, p \eta^{2}=0.07\right]$, and of Stimulus $\left[F(1,24)=0.02 ; P=0.9, p \eta^{2}=0.01\right]$, and the Group by Stimulus $\left[F(2,24)=1.69 ; P=0.2, p \eta^{2}=0.07\right]$, Session by Stimulus $\left[F(1,24)=1.81 ; P=0.2, p \eta^{2}=0.07\right]$, and Group by Session by Stimulus $\left[F(2,24)=0.23 ; P=0.6, p \eta^{2}=0.01\right]$ interactions were not significant.

The ANCOVA showed that the main effect of the covariate Lesion size, $\left[F(1,11)=2.38 ; P=0.2, p \eta^{2}=0.18\right]$ failed to reach significance. Moreover, Lesion size did not significantly interact with the main effects of Session $[F(1,11)=0.04 ; P=0.8$, $\left.p \eta^{2}=0.01\right]$, and of Stimulus $\left[F(1,11)=0.12 ; P=0.7, p \eta^{2}=0.01\right]$, as well as with the Session by Stimulus $[F(1,11)=1.08 ; P=0.3$, $\left.p \eta^{2}=0.09\right]$ interaction. Importantly, the main effect of Session was still significant $\left[F(1,11)=14.89, P=0.01, p \eta^{2}=0.58\right]$. Hence, lesion size did not influence the performance of RHD patients.
Pearson's correlation analysis between the bisection error in the real and in the fake forearm conditions, for both the preexposure and the post-exposure sessions were also performed. In healthy participants, there was no significant correlation between real and fake forearm bisections both in the pre-exposure session $(r=0.42, P=0.2)$, and in the post-exposure session $(r=0.11$, $P=0.7)$. Instead, in RHD patients, there was a positive correlation between the bisection error in the real and in the fake forearm conditions in the pre-exposure $(r=0.72, P<0.01)$, but not in the post-exposure session $(r=0.42, P=0.1)$. Moreover, the amount of the aftereffects (post-exposure minus pre-exposure pointing error) was not correlated with the amount of shift in the body bisection task (post-exposure minus pre-exposure deviation error) both in controls (real forearm, $r=-0.14, P=0.7$; fake forearm, $r=-0.63, P=0.06$ ), and in RHD patients (real forearm, $r=-0.12, P=0.7$; fake forearm, $r=0.17, P=0.5)$. It may be noted that in controls a negative correlation between the size of the aftereffects and the bisection error for the fake stimulus approached significance.

\section{COMPARISON BETWEEN PATIENTS AND CONTROLS}

As shown by Figure 4A, before PA, 10 out of 16 RHD patients showed some degree of difference in the amount of error in one or both bisection conditions, as compared to controls. In particular, five patients had a significantly defective performance only in the fake forearm condition, showing a rightward error: $\mathrm{P} 2=+12 \%$ of deviation error, $t(9)=3.18, P<0.01 ; \mathrm{P} 5=+11 \%$ of deviation error, $t(9)=2.86, P<0.01$; P6 $=+11 \%$ of deviation error, $t(9)=2.86, P<0.01 ; \mathrm{P} 15=+11 \%, t(9)=2.86$, $P<0.01 ; \mathrm{P} 16=+13 \%, t(9)=3.49, P<0.01$. Instead, the performances of $\mathrm{P} 8, \mathrm{P} 10, \mathrm{P} 11, \mathrm{P} 12$, and $\mathrm{P} 14$ were defective for both the real and the fake forearm bisections: $\mathrm{P} 8=$ real, $-7 \%, t(9)=-2.15, P<0.03$, fake, $+11 \%, t(9)=2.86, P<0.01$; $\mathrm{P} 10=$ real, $+28 \%, t(9)=6.19, P<0.01$, fake, $+22 \%, t(9)=6.36$, $P<0.01 ; \mathrm{P} 11=$ real, $+17 \%, t(9)=3.58, P<0.01$, fake, $+19 \%$, $t(9)=5.4, P<0.01 ; \mathrm{P} 12=$ real, $+14 \%, t(9)=2.86, P<0.01$, fake, $+9 \%, t(9)=2.22, P<0.02$; P14 $=$ real, $+16 \%, t(9)=3.37$, $P<0.01$, fake, $+19 \%, t(9)=5.4, P<0.01$. P5 and P8 also showed a significant difference between the two bisection conditions, with a greater rightward error for the fake forearm: $\mathrm{P} 5=+11 \%$, $t(9)=2.77, P<0.02 ; \mathrm{P} 8=+18 \%, t(9)=4.09, P<0.01$.

We also compared the performance of patients with or without USN in the two bisection conditions (real forearm vs. fake forearm) via an ANOVA with Group, as a between-subjects factor, and Stimulus, as a within-subjects factor; the dependent measure was the mean deviation error before PA. Only the factor Group was significant $\left[F(1,14)=8.15 ; P<0.01, p \eta^{2}=0.92\right]$ : patients with USN showed a larger rightward bisection error $(+12 \%)$ in both the real and the fake forearm conditions, as compared to patients without USN $(+3 \%)$. Other effects were not significant: Stimulus $\left[F(1,14)=2.38 ; \mathrm{P}=0.1, p \eta^{2}=0.15\right]$, Group by Stimulus interaction $\left[F(1,14)=0.94 ; P=0.4, p \eta^{2}=0.03\right]$.

With respect to the effects of PA on bisection performance (i.e., the difference in the deviation errors between the post-exposure and the pre-exposure sessions, see Figure 4B), six RHD patients differed from controls in the fake forearm, showing a greater leftward error: $\mathrm{P} 2=-13 \%, t(9)=-3.18, P<0.01$, $\mathrm{P} 8=-21 \%$, 
A

\section{Body bisection}

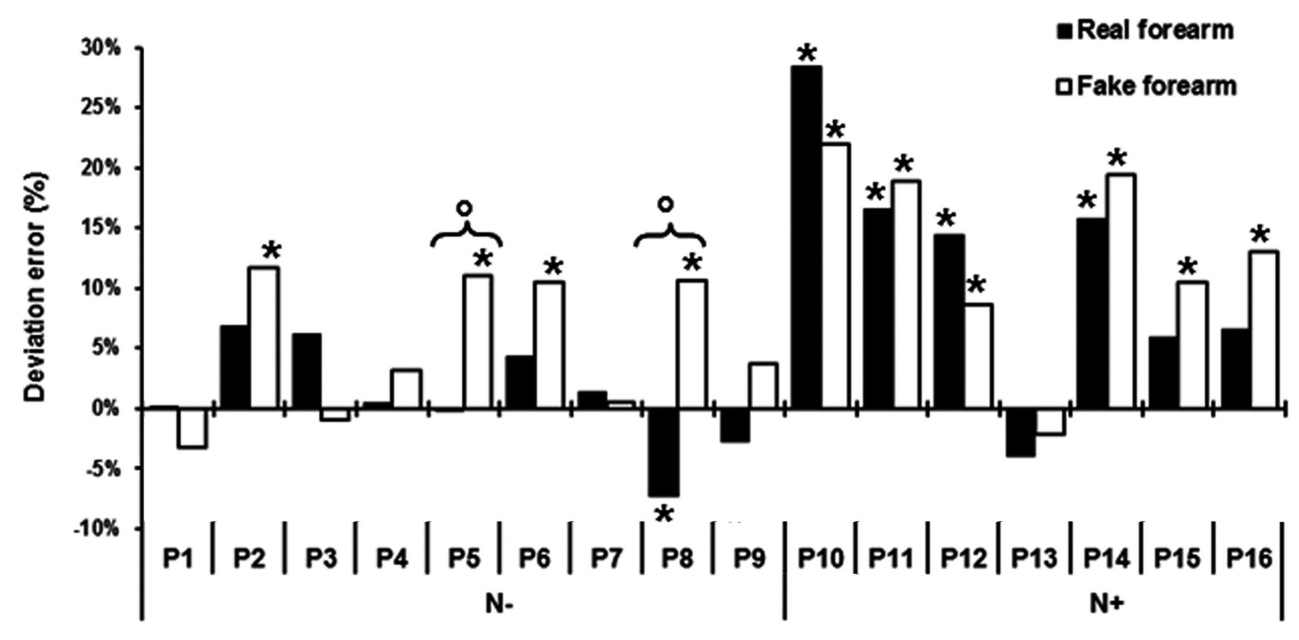

B

PA effect on forearm bisection

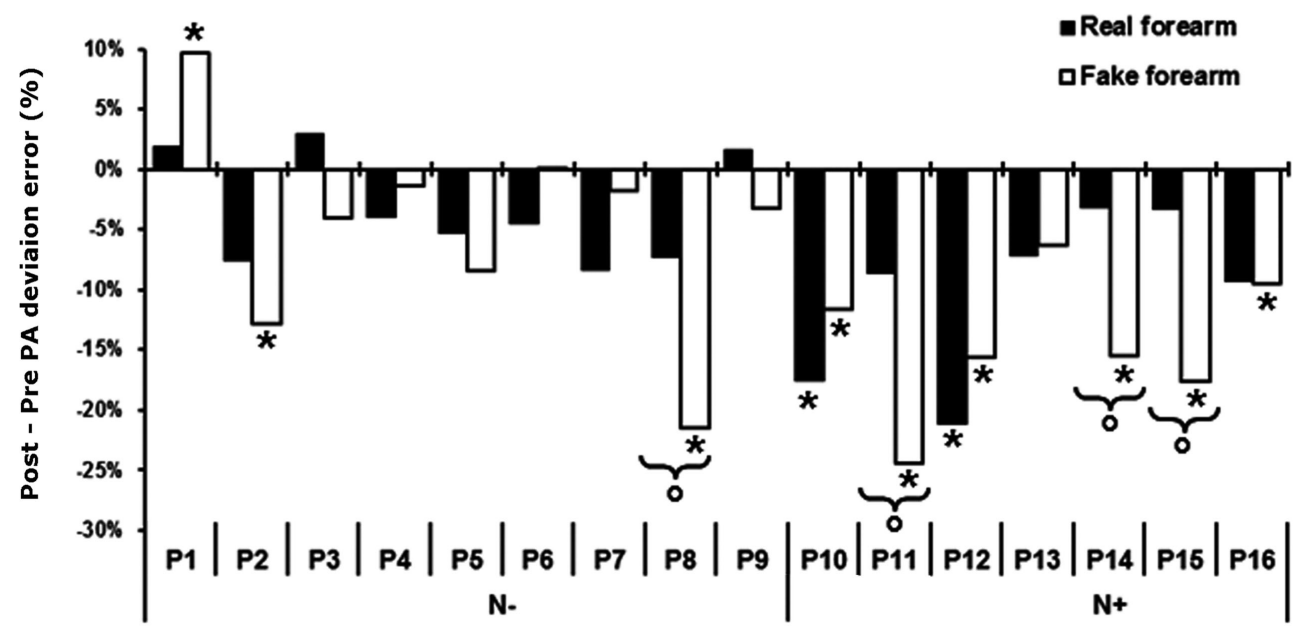

FIGURE 4 | (A) Pre-exposure condition: mean percent deviation error by stimulus condition in each of the 16 RHD patients. (B) Effects of PA on forearm bisection, i.e., difference in the deviation error between post-exposure and pre-exposure to prisms (post minus pre PA), for the real and the fake forearm conditions in each of the 16 patients. A negative score indicates a leftward, PA-induced, net effect, a positive score a rightward effect. Asterisk: significant difference between each patient's score and the mean score of the control group for each stimulus condition. Circles and brackets: significant difference between fake and real forearm bisection in the individual patient, as compared to the same average difference in the control group. $\mathrm{N}_{-}$, patients without USN; $\mathrm{N}_{+}$, patients with USN. $t(9)=-5.72, P<0.01, \mathrm{P} 11=-24 \%, t(9)=-6.67, P<0.01$; $\mathrm{P} 14=-16 \%, t(9)=-4.13, P<0.01 ; \mathrm{P} 15=-18 \%, t(9)=-4.77$, $P<0.01 ; \mathrm{P} 16=-9 \%, t(9)=-1.9, P<0.04$. P1 did not show the typical leftward aftereffects, exhibiting instead a significant rightward deviation in fake forearm bisection after prism removal $[+10 \%, t(9)=4.13, P<0.01]$. Two patients showed significantly larger effects of PA in both the real and fake forearm bisections, which did not differ $(P>0.1): \mathrm{P} 10=$ real forearm, $-18 \%$, $t(9)=-3.81, P<0.01$, fake forearm, $-12 \%, t(9)=-2.86, P<$ $0.01 ; \mathrm{P} 12=$ real forearm, $-21 \%, t(9)=-4.53, P<0.01$, fake forearm, $-16 \%, t(9)=-4.13, P<0.01$. A significant difference between the aftereffects in the two forearm conditions was found in four patients, with a greater leftward shift for the fake forearm: P8 $=14 \%, t(9)=2.85, P<0.02 ; \mathrm{P} 11=-16 \%, t(9)=3.14$, $P<0.01 ; \mathrm{P} 14=-12 \%, t(9)=2.45, P<0.04 ; \mathrm{P} 15=-14 \%$, $t(9)=2.84, P<0.02$.

An ANOVA with Group (patients with vs. without USN) and Stimulus (real forearm vs. fake forearm) as main factors, run on the difference in the deviation error between post-exposure and preexposure to PA (post-PA minus pre-PA), showed a significant effect only of the factor Group $\left[F(1,14)=9.22 ; P<0.01, p \eta^{2}=0.85\right]$ : patients with USN showed a larger PA-induced leftward bias 
$(-12 \%)$, as compared to patients without USN $(-4 \%)$. Other effects were not significant: Stimulus $[F(1,14)=1.86 ; P=0.2$, $\left.p \eta^{2}=0.12\right]$, Group by Stimulus interaction $[F(1,14)=0.48$; $\left.P=0.5, p \eta^{2}=0.02\right]$.

\section{CORRELATIONS BETWEEN FOREARM BISECTION AND CLINICAL SCORES IN RHD PATIENTS}

As reported in Tables 3 and 4, in RHD patients, only two significant correlations were found: the amount of visual deficit was positively correlated with the amount of the deviation error in both the real $(r=0.76, P<0.01)$ and the fake $(r=0.77, P<$ 0.01 ) forearm conditions. Instead, the amount of proprioceptive deficit (i.e., position sense) was positively correlated with bisection performance in the fake forearm $(r=0.64, P<0.01)$, but not in the real forearm ( $r=0.41, P=0.2)$ condition. No other significant correlations between performances in the experimental task and clinical scores were found.

\section{DISCUSSION}

Two main results emerge from this study. First, in RHD patients, with and without USN, and in neurologically healthy participants, bisection performance is overall similar for one's own forearm and for the fake forearm, as shown by the group analyses. As expected in a bisection task (see, e.g., Mancini et al., 2011, for a line bisection study comparing the performances of RHD patients with and without USN), RHD patients with USN make greater rightward errors in either stimulus conditions (i.e., real and fake forearm), than those committed by RHD patients without USN. These results are qualified by the single-patient analyses, which show that, as compared to healthy controls, 6 out of the 16 RHD patients (namely, P2, P5, P6, P8; P15, and P16, see Figure 4A) exhibit a pathological rightward bisection error only for the fake forearm, being statistically unimpaired for the real forearm (except for patient $\mathrm{P} 8$ who shows a defective performance also with the real forearm, but with a leftward bisection bias). Two patients (P5 and P8) show a significant difference between the real and the fake forearm bisections, with a greater rightward error in the fake forearm condition. As found in our previous study (Sposito et al., 2010), the forearm bisection deficit was unrelated to personal neglect (see Table 1).

The second finding is that all participants show PA and aftereffects. Overall, PA diminishes the rightward bisection bias in RHD patients in both real and fake forearm conditions, with no significant effects in control participants. The PA-induced leftward

Table 3 | Correlation matrix between the bisection performances of RHD patients in the real and the fake forearm conditions, pre- and post-PA, and the demographic, neurological, anosognosia, and position sense (left forearm) scores.

\begin{tabular}{|c|c|c|c|c|c|c|c|c|c|}
\hline & \multirow[t]{2}{*}{ Age } & \multirow[t]{2}{*}{ Length of illness } & \multicolumn{3}{|c|}{ Neurological examination } & \multicolumn{3}{|c|}{ Anosognosia } & \multirow[t]{2}{*}{ Position sense } \\
\hline & & & V & SS & M & $\mathbf{v}$ & SS & M & \\
\hline (pre-exposure) & $P=0.4$ & $P=0.2$ & $P<0.01^{*}$ & $P=0.2$ & $P=0.6$ & $P=0.2$ & $P=0.3$ & $P=0.2$ & $P=0.2$ \\
\hline Fake forearm Bisection & $r=0.35$ & $r=0.47$ & $r=0.77^{*}$ & $r=0.47$ & $r=0.16$ & $r=0.11$ & $r=0.46$ & $r=0.48$ & $r=0.64$ \\
\hline (pre-exposure) & $P=0.2$ & $P=0.1$ & $P<0.01^{*}$ & $P=0.1$ & $P=0.7$ & $P=0.7$ & $P=0.1$ & $P=0.09$ & $P=0.01^{*}$ \\
\hline (post-exposure) & $P=0.9$ & $P=0.07$ & $P=0.06$ & $P=0.8$ & $P=0.8$ & $P=0.7$ & $P=0.9$ & $P=0.9$ & $P=0.9$ \\
\hline Fake forearm Bisection & $r=-0.14$ & $r=0.18$ & $r=0.07$ & $r=0.02$ & $r=-0.06$ & $r=-0.05$ & $r=-0.1$ & $r=-0.17$ & $r=-0.09$ \\
\hline (post-exposure) & $P=0.7$ & $P=0.6$ & $P=0.9$ & $P=0.7$ & $P=0.8$ & $P=0.8$ & $P=0.6$ & $P=0.5$ & $P=0.8$ \\
\hline
\end{tabular}

Asterisk: significant correlation

Table 4 | Correlation matrix between the bisection performances of RHD patients in the real and the fake forearm conditions, pre- and post-PA, and neuropsychological scores.

\begin{tabular}{|c|c|c|c|c|c|c|c|}
\hline & \multirow[t]{2}{*}{ Line bisection } & \multicolumn{3}{|c|}{ Cancelation } & \multirow[t]{2}{*}{ Drawing } & \multirow[t]{2}{*}{ Reading } & \multirow[t]{2}{*}{ Personal neglect } \\
\hline & & Bell & Letter & Star & & & \\
\hline \multirow[t]{2}{*}{ Real forearm bisection (pre-exposure) } & $r=-0.03$ & $r=-0.44$ & $r=-0.48$ & $r=-0.45$ & $r=-0.31$ & $r=-0.31$ & $r=-0.42$ \\
\hline & $P=0.9$ & $P=0.2$ & $P=0.1$ & $P=0.1$ & $P=0.3$ & $P=0.3$ & $P=0.2$ \\
\hline \multirow[t]{2}{*}{ Fake forearm bisection (pre-exposure) } & $r=-0.02$ & $r=-0.43$ & $r=-0.29$ & $r=-0.45$ & $r=-0.36$ & $r=-0.21$ & $r=-0.38$ \\
\hline & $P=0.9$ & $P=0.2$ & $P=0.3$ & $P=0.3$ & $P=0.5$ & $P=0.5$ & $P=0.2$ \\
\hline \multirow[t]{2}{*}{ Real forearm bisection (post-exposure) } & $r=-0.02$ & $r=-0.39$ & $r=-0.18$ & $r=-0.45$ & $r=-0.31$ & $r=-0.11$ & $r=-0.31$ \\
\hline & $P=0.9$ & $P=0.2$ & $P=0.6$ & $P=0.3$ & $P=0.7$ & $P=0.5$ & $P=0.3$ \\
\hline \multirow[t]{2}{*}{ Fake forearm bisection (post-exposure) } & $r=-0.21$ & $r=-0.23$ & $r=0.05$ & $r=-0.05$ & $r=-0.11$ & $r=-0.11$ & $r=0.05$ \\
\hline & $P=0.5$ & $P=0.5$ & $P=0.8$ & $P=0.8$ & $P=0.7$ & $P=0.7$ & $P=0.9$ \\
\hline
\end{tabular}

No significant correlations were found. 
bias in the real and fake conditions is greater in patients with USN, than in patients without USN. Moreover, analyses of the individual patients' performance, compared to healthy controls, show that, in 6 out of 16 RHD patients (P2, P8, P11, P14-16), PA reduces the rightward bisection bias in the fake forearm condition only. Furthermore, four patients (P8, P11, P14, and P15) show a significant difference between the effects of PA in the two stimulus conditions, namely: a greater increase of the PA-induced leftward bias for fake forearm bisection. Finally, in two RHD patients with USN (P10 and P12) PA brought about the leftward bias in both forearm conditions.

\section{REAL AND FAKE FOREARM BISECTION}

The overall lack of differences between the biases for the real and the fake forearm bisection tasks in right-brain-damaged and healthy participants shown by the group analysis, and the similarities of the effects of PA on the two types of stimuli, suggest that, at least as the present bisection paradigm is concerned, a shared spatial representation of real and fake body parts is available. The vision of a body part, as a highly specific and familiar object, may activate its prototypical standard representation, including spatial information about its length, thus allowing a comparable bisection performance for one's own forearm, and for a fake forearm, likely based on a visual analysis of the stimulus. The crucial role of visual inputs is supported by the significant correlation between the bisection performances in the two conditions, and the presence of a visual half-field deficit: the greater is the visual impairment, the larger is the bisection error in both real and fake forearm conditions. This finding is also consistent with the evidence that RHD patients with left USN and hemianopia make a greater rightward error in line bisection than USN patients without hemianopia (D'Erme et al., 1987; Doricchi and Angelelli, 1999; Daini et al., 2002). Notably, however, in RHD patients line bisection performance does not correlate with real and fake forearm bisection, in line with the recent previous evidence that different spatial processes are involved in the representation of extent, as assessed by bisection, of bodily and extra-personal objects (Sposito et al., 2010). Also fake and real forearm bisection performances do not correlate in healthy control participants, suggesting at least partly independent underlying processes, although caution is in order, since this conclusion is based on a negative finding. Interestingly, a significant correlation between the bisection performances in fake and real forearm conditions was found in RHD patients before, but not after, PA: this finding is likely to reflect the rightward-USN related bias shown by RHD patients, which affects both forearm types. The rightward error may however be differentially modulated by PA, according to forearm type, with effects confined to and greater in the fake forearm, as shown by the individual patients' analyses.

Importantly, we also found in RHD patients that an impaired position sense was related to the amount of deviation in fake, but not in real, forearm bisection. There is an important bodily illusion that might be relevant to explain why proprioceptive deficits are related to the ability of coding the spatial extension of the fake forearm. Visual capture of limb position is the phenomenon of perceiving the felt position of a limb to occupy the illusorily seen position when other sensory cues, such as proprioceptive inputs, are in conflict (Giummarra et al., 2008). Proprioceptive input regarding the positions of body parts can drift them from their actual position when they are hidden from view (as it occurs in our experimental task; Gross and Melzack, 1978; Giummarra et al., 2008). An important example of this effect is the rubber hand illusion (RHI). The RHI is evoked when the participant watches a rubber hand being stroked, while their own unseen hand is stroked in synchrony. This results in feeling ownership over the rubber hand, and induces a relocation of the perceived position of one's unseen own hand toward that of the rubber hand (Botvinick and Cohen, 1998). However, the rubber hand produces no such modulatory effect when placed in an anatomically implausible posture, that is totally inconsistent with the real hands' actual posture. Thus, while purely visual information (i.e., the sight of a fake forearm) can dominate slightly discrepant proprioception (as in the case of the fake forearm, placed, as in our experiment, in a plausible position), a proprioceptive deficit may reduce the impact of vision when the visual information about the position of body parts is inconsistent with proprioception, and with the representation of the body schema. This multisensory, body-related mechanism may explain the similar performances in real and fake forearm bisections: under normal conditions, as in neurologically unimpaired controls (see also Sposito et al., 2010), the sight of a fake forearm in a possible anatomical location for the real forearm determines a visual capture effect of limb position; as a consequence, the fake forearm is processed as the participant's own real forearm, for the purpose of bisection. A different scenario emerges when position sense is impaired by brain damage: the visual capture of the fake forearm is compromised, as the disrupted proprioceptive input regarding the position of the real forearm cannot be drifted to the location of the fake forearm. Now, since the fake forearm is no longer processed as the real forearm, belonging to the participant's own body, the fake forearm ceases to benefit from a multisensory (visual-proprioceptive) code, that, in its proprioceptive component, is putatively crucial for real body parts, but is not available to fake body parts [unless there is embodiment of the fake forearm, see Giummarra et al., 2008]. Under these conditions, the fake forearm is now encoded as a mere extra-personal object, and becomes more susceptible to the spatial disruption brought about by damage to the right hemisphere, in line with previous evidence (Sposito et al., 2010).

This finding supports the idea that, although the visual appearance of the fake forearm as a body part may ensure, per se, a better spatial analysis as compared to a neutral object (Sposito et al., 2010), the proprioceptive input always plays a role in the spatial analysis of bodily related visual information.

The dissociations found in RHD patients further indicate that the metrics of real and fake body parts are supported by discrete spatial processes, that may be selectively disrupted by a brain lesion. As shown in Figure 4A, even some patients without USN show a selective impairment for fake, but not for real, forearm bisection (P2, P5, P6, and P8, the last patient, however, exhibits a leftward bias, namely no right USN, with the real forearm). Also, two patients with USN (P15, P16) are impaired in the fake forearm condition only, and an opposite dissociation is not found, suggesting that the representation of the length of self-body parts 
is more reliable and resistant to the spatial disruption induced by a damage to the right hemisphere (see also Sposito et al., 2010).

Our findings are also in line with a dyadic model of body representation proposed in the literature, since the seminal studies of Bonnier (1905, see also Vallar and Rode, 2009), and Head and Holmes (1911; see for reviews: Berlucchi and Aglioti, 1997; Vallar and Papagno, 2003; Maravita, 2006; De Vignemont, 2010). A distinction has been drawn between a Body Schema, mainly constructed on somatosensory-proprioceptive and tactile information, which serves the guidance of actions, and a Body Image, which relies mainly on visual and tactile information, and mainly serves perception. Neuropsychological evidence shows that the Body Schema is actually dissociable from the Body Image. For instance, patients with USN are generally still able to perform non-conscious and automatic movements with neglected body parts, hence showing an intact Body Schema. Rather, the personal or bodily manifestations of USN appear to result from distortions of the Body Image, particularly affecting the conscious awareness of parts of the body (Sirigu et al., 1991; Gallagher and Cole, 1995; Coslett, 1998; Coslett et al., 2002; Gallagher, 2005; Maravita, 2006; De Vignemont, 2010; Preston and Newport, 2011). In this context, one may speculate that the Body Schema plays a pivotal role in the multisensory analysis of the metric of real body parts, whereas the visuo-spatial coding of fake body parts is a process pertaining to the impaired Body Image. The significant correlation between the severity of the proprioceptive deficit and that of the bisection error for the fake forearm suggests that, under unimpaired conditions, an object such as a fake body part may be processed as a real body part, namely as a part of the Body Schema, through computations involving position sense.

With respect to the neural correlates of deficits of real and fake forearm bisection, the limited number of patients, the different etiologies of the lesions, and the fact that some lesion images were not available for mapping, prevent definite conclusions. It may be cautiously noted, however, that the damage of the four RHD patients (P10, P11, P12, and P14) showing an impairment in the two bisection conditions is anterior-subcortical, affecting frontal areas, the insular cortex and subcortical structures including the putamen (see Figure 1). The frontal premotor cortex (PMC) and the putamen are known to instantiate a multisensory representation of peripersonal space. This representation is body part-centered, and it integrates visual, somatosensory, and proprioceptive information regarding stimulus location relative to the body (Graziano and Gross, 1993, 1995; Graziano et al., 1994; Maravita et al., 2003b). Moreover, in healthy humans, the experimental manipulation of ownership of individual body parts or of the whole body is associated with activity in PMC, the intraparietal sulcus (IPS), and the putamen (Ehrsson et al., 2004; Petkova et al., 2011). Finally, the insula has been definitely implicated in neurological disorders including anosognosia for hemiplegia, the sense of body ownership, the sense of agency and out-of-the-body experiences (Karnath et al., 2005; Baier and Karnath, 2008; Craig, 2009; Vallar and Ronchi, 2009; Berlucchi and Aglioti, 2010). Therefore, a damage to this network might disrupt the multisensory coding of the spatial extension of self-body parts, and the visual capture effect for fake body parts.
On the other hand, neuroimaging data suggest the existence of a posterior network concerned with a predominately visual representation of body parts; this network might play a crucial role in the selective deficit for fake forearm bisection, with spared real forearm. Indeed, the lateral occipito-temporal cortex includes a category-specific cortical region, the extrastriate body area (i.e., EBA), which responds in a selective manner to the visual presentation of real or stylized images of human body parts belonging to the participant or to someone else (Downing et al., 2001, 2006; Chan et al., 2004). Patients with posterior lesions including either the left or the right EBA are impaired in the visual processing of bodily forms, but not of bodily actions, while patients with anterior brain lesions, including either the left or the right ventral PMC, show an opposite pattern of deficits (Moro et al., 2008). Moreover, in humans, the lateral occipital cortex and the posterior part of the IPS (i.e., adjoining the transverse occipital sulcus) represent the hand-centered space in a predominantly visual manner, regardless of whether the hand is real or illusory, and with no relevant contribution of proprioceptive information about hand position (Makin et al., 2007). Instead, the anterior part of the IPS uses proprioceptive multisensory information in representing peri-hand space (Bolognini and Maravita, 2007, 2011; Makin et al., 2007). It may be noted that the one patient (P16) with a mainly posterior (temporo-occipito-parietal, see Figure 1) lesion is significantly impaired in the fake condition only, as compared with control participants. Also anterior lesions, however, may bring about this pattern of deficit (P2).

\section{PA AND AFTEREFFECTS}

All participants showed aftereffects after PA, as assessed by the invisible pointing task, and the size of the aftereffects (i.e., the difference between pre- and post-PA invisible pointing performance) was comparable in the RHD and control participants. A recent study (Sarri et al., 2008), using a visual open loop pointing task (broadly comparable to our invisible pointing task), found that the error of patients with USN was comparable to that of neurologically unimpaired participants; crucially, the size of the aftereffects was comparable in patients with USN and in controls. A different pattern emerges when a dependent variable which has been considered an index of the neglect syndrome is used, namely the subjective straight ahead (Jeannerod and Biguer, 1987; Karnath, 1994, 1997; but see Farnè et al., 1998). Neglect patients show a larger rightward shift of the subjective straight ahead, assessed with participants being blindfolded, and greater effects of PA on this variable, as compared to healthy participants (Rossetti et al., 1998; Sarri et al., 2008). These findings may be interpreted as an indication that the disproportionate rightward shift of the subjective straight ahead is a pathological manifestation of USN, though it is not systematically found (Chokron and Bartolomeo, 1997; Farnè et al., 1998; Chokron, 2003); accordingly, in USN patients the effects of PA may be larger than in unimpaired participants (Sarri et al., 2008). With respect to line bisection performance, several studies (e.g., Colent et al., 2000; Berberovic and Mattingley, 2003; Michel et al., 2003; Fortis et al., 2011) have found a small neglect-like rightward bias on line bisection and Landmark tasks in normal participants following exposure to leftward, but not rightward, optical displacement; in patients with USN 
some studies show a reduction of the rightward bias (e.g., Rossetti et al., 1998; Pisella et al., 2002; Redding et al., 2005, for review), others do not (e.g., Luauté et al., 2006; Nys et al., 2008; Fortis et al., 2010). In the present study, PA diminishes the rightward bisection bias only in RHD patients in both stimulus conditions (real and fake forearm, with no effects in control participants, supporting the view that these deficits are manifestations of the neglect syndrome brought about by right brain damage (Sposito et al., 2010). This is further supported by the comparison between patients with and without USN, which shows a greater PA effect on both the fake forearm and real forearm bisections in USN patients. On the other hand, the amount of the aftereffects is not correlated with the amount of shift in the real and fake bisection tasks both in controls, and in RHD patients. Notably, the present study, unlike the abovementioned previous reports (Rossetti et al., 1998; Sarri et al., 2008) included also RHD patients without USN, in addition to the patients with USN and the healthy participants.

\section{REFERENCES}

Baier, B., and Karnath, H. O. (2008). Tight link between our sense of limb ownership and self-awareness of actions. Stroke 39, 486-488.

Berberovic, N., and Mattingley, J. B. (2003). Effects of prismatic adaptation on judgments of spatial extent in peripersonal and extrapersonal space. Neuropsychologia 41, 493-503.

Berlucchi, G., and Aglioti, S. (1997). The body in the brain: neural bases of corporeal awareness. Trends $\mathrm{Neu}$ rosci. 20, 560-564.

Berlucchi, G., and Aglioti, S. M. (2010). The body in the brain revisited. Exp. Brain Res. 200, 25-35.

Bisiach, E., Bulgarelli, C., Sterzi, R., and Vallar, G. (1983). Line bisection and cognitive plasticity of unilateral neglect of space. Brain Cogn. 2, 32-38.

Bisiach, E., and Faglioni, P. (1974). Recognition of random shapes by patients with unilateral lesions as a function of complexity, association value and delay. Cortex 10, 101-110.

Bisiach, E., Perani, D., Vallar, G., and Berti, A. (1986a). Unilateral neglect: personal and extra-personal. $\mathrm{Neu}$ ropsychologia 24, 759-767.

Bisiach, E., Vallar, G., Perani, D., Papagno, C., and Berti, A. (1986b). Unawareness of disease following lesions of the right hemisphere: anosognosia for hemiplegia and anosognosia for hemianopia. $\mathrm{Neu}$ ropsychologia 24, 471-482.

Bisiach, E., and Vallar, G. (2000). "Unilateral neglect in humans," in Handbook of Neuropsychology, 2nd Edn, eds F. Boller, J. Grafman, and G. Rizzolatti (Amsterdam: Elsevier), 459-502.
Bolognini, N., and Maravita, A. (2007). Proprioceptive alignment of visual and somatosensory maps in the posterior parietal cortex. Curr. Biol. 17, 1890-1895.

Bolognini, N., and Maravita, A. (2011). Uncovering multisensory processing through non-invasive brain stimulation. Front. Psychol. 2:46. doi:10.3389/fpsyg.2011.00046

Bonnier, P. (1905). L'aschématie. Rev. Neurolog. (Paris) 13, 605-609.

Botvinick, M., and Cohen, J. (1998). Rubber hands 'feel' touch that eyes see. Nature 391, 756.

Chan, A. W., Peelen, M. V., and Downing, P. E. (2004). The effect of viewpoint on body representation in the extrastriate body area. Neuroreport 15, 2407-2410.

Chokron, S. (2003). Right parietal lesions, unilateral spatial neglect, and the egocentric frame of reference. Neuroimage 20(Suppl. 1), S75S81.

Chokron, S., and Bartolomeo, P. (1997). Patterns of dissociation between left hemineglect and deviation of the egocentric reference. Neuropsycholo-

Cohen, J. (1973). Eta-squared and partial Eta-squared in fixed factor anova designs. Educ. Psychol. Meas. 33, 107-112.

Colent, C., Pisella, L., Bernieri, C., Rode, G., and Rossetti, Y. (2000). Cognitive bias induced by visuo-motor adaptation to prisms: A simulation of unilateral neglect in normal individuals? Neuroreport 11, 1899-1902.

Committeri, G., Pitzalis, S., Galati, G., Patria, F., Pelle, G., Sabatini, U., Castriota-Scanderbeg, A., Piccardi, L., Guariglia, C., and Pizzamiglio, L. (2007). Neural bases of personal and gia 35, 1503-1508.

Overall, these novel results demonstrate that in RHD patients PA affects the metric representation of the body, as indexed by forearm bisection performance, supporting the view that their rightward bias in real and fake forearm bisection is a manifestation of the left USN syndrome caused by the right hemispheric damage. Finally, the analysis of the performances of individual patients (showing in a number of patients effects on fake body bisection, and not on real body bisection) supports the view that the representations and processing of these two types of objects are, at least in part, independent.

\section{ACKNOWLEDGMENTS}

This work was supported in part by MIUR and FAR grants from the University of Milano-Bicocca to Nadia Bolognini, Angelo Maravita, and Giuseppe Vallar, and by a Ricerca Corrente Grant from the IRCCS Italian Institute for Auxology to Giuseppe Vallar. We are grateful to Dr. Roberta Ronchi, $\mathrm{PhD}$, for her assistance in patients' selection and lesion mapping.

extrapersonal neglect in humans. Brain 130, 431-441.

Coslett, H. B. (1998). Evidence for a disturbance of the body schema in neglect. Brain Cogn. 37, 527-544.

Coslett, H. B., Saffran, E. M., and Schwoebel, J. (2002). Knowledge of the human body: a distinct semantic domain. Neurology 59, 357-363.

Craig, A. D. (2009). How do you feelnow? The anterior insula and human awareness. Nat. Rev. Neurosci. 10, 59-70.

Crawford, J. R., and Garthwaite, P. H. (2005). Testing for suspected impairments and dissociations in single-case studies in neuropsychology: evaluation of alternatives using Monte Carlo simulations and revised tests for dissociations. $\mathrm{Neu}$ ropsychology 19, 318-331.

Daini, R., Angelelli, P., Antonucci, G., Cappa, S. F., and Vallar, G. (2002). Exploring the syndrome of spatial unilateral neglect through an illusion of length. Exp. Brain Res. 144, 224-237.

De Vignemont, F. (2010). Body schema and body image - pros and cons. Neuropsychologia 48, 669-680.

D'Erme, P., De Bonis, C., and Gainotti, G. (1987). Influenza dell'emiinattenzione e dell'emianopsia sui compiti di bisezione di linee nei pazienti cerebrolesi. Arch. Psicol. Neurol. Psichiatr. 48, 193-207.

Diller, L., and Weinberg, J. (1977). "Hemi-inattention in rehabilitation. The evolution of a rational remediation program," in Hemiinattention and Hemisphere Specialization. Advances in Neurology, eds E. A. Friedland and R. P.
Weinstein (New York: Raven Press), 62-82.

Doricchi, F., and Angelelli, P. (1999). Misrepresentation of horizontal space in left unilateral neglect: role of hemianopia. Neurology 52, 1845-1852.

Downing, P. E., Jiang, Y., Shuman, M., and Kanwisher, N. (2001). A cortical area selective for visual processing of the human body. Science 293, 2470-2473.

Downing, P. E., Peelen, M. V., Wiggett, A. J., and Tew, B. D. (2006). The role of the extrastriate body area in action perception. Soc. Neurosci. 1, 52-62.

Ehrsson, H. H., Spence, C., and Passingham, R. E. (2004). That's my hand! Activity in premotor cortex reflects feeling of ownership of a limb. Science 305, 875-877.

Farnè, A., Ponti, F., and Làdavas, E. (1998). In search of biased egocentric reference frames in neglect. Neuropsychologia 36, 611-623.

Farnè, A., Rossetti, Y., Toniolo, S., and Làdavas, E. (2002). Ameliorating neglect with prism adaptation: visuo-manual and visuoverbal measures. Neuropsychologia 40, 718-729.

Fortis, P., Goedert, K. M., and Barrett, A. M. (2011). Prism adaptation differently affects motor-intentional and perceptual-attentional biases in healthy individuals. Neuropsychologia 49, 2718-2727.

Fortis, P., Maravita, A., Gallucci, M., Ronchi, R., Grassi, E., Senna, I., Olgiati, E., Perucca, L., Banco, E., Posteraro, L., Tesio, L., and Vallar, G. (2010). Rehabilitating patients with left spatial neglect by prism exposure during a visuomotor activity. Neuropsychology 24, 681-697. 
Frassinetti, F., Angeli, V., Meneghello, F., Avanzi, S., and Làdavas, E. (2002). Long-lasting amelioration of visuospatial neglect by prism adaptation. Brain 125, 608-623.

Gainotti, G., Messerli, P., and Tissot, R. (1972). Qualitative analysis of unilateral spatial neglect in relation to laterality of cerebral lesions. J. Neurol. Neurosurg. Psychiatry 35, 545-550.

Gallagher, S., and Cole, J. (1995). Body schema and body image in a deafferented subject. J. Mind Behav. 16, 369-390.

Gallagher, S. (ed.). (2005). How the body shapes the mind. New York: Oxford University Press.

Gauthier, L., Dehaut, F., and Joanette, Y. (1989). The bells test: a quantitative and qualitative test for visual neglect. Int. J. Clin. Neuropsychol. 11, 49-54.

Giummarra, M. J., Gibson, S. J., Georgiou-Karistianis, N., and Bradshaw, J. L. (2008). Mechanisms underlying embodiment, disembodiment and loss of embodiment. Neurosci. Biobehav. Rev. 32, 143-160.

Graziano, M. S., and Gross, C. G. (1993). A bimodal map of space: somatosensory receptive fields in the macaque putamen with corresponding visual receptive fields. Exp. Brain Res. 97, 96-109.

Graziano, M. S., and Gross, C. G. (1995). "The representation of extrapersonal space: as possible role for bimodal, visual-tactile neurons," in The Cognitive Neurosciences, ed. M. S. Gazzaniga (Cambridge, MA: MIT Press), 1021-1034.

Graziano, M. S., Yap, G. S., and Gross, C. G. (1994). Coding of visual space by premotor neurons. Science 266, 1054-1057.

Gross, Y., and Melzack, R. (1978). Body image: dissociation of real and perceived limbs by pressure-cuff ischemia. Exp. Neurol. 61, 680-688.

Guariglia, C., and Antonucci, G. (1992). Personal and extrapersonal space: a case of neglect dissociation. Neuropsychologia 30, 1001-1009.

Halligan, P. W., and Marshall, J. C. (1994). Focal and global attention modulate the expression of visuospatial neglect: a case study. $\mathrm{Neu}$ ropsychologia 32, 13-21.

Head, H., and Holmes, G. (1911). Sensory disturbances from cerebral lesions. Brain 34, 102-254.

Heilman, K. M., Watson, R. T., and Valenstein, E. (2003). "Neglect and related disorders," in Clinical $\mathrm{Neu}$ ropsychology, eds K. M. Heilman \& E. Valenstein (New York: Oxford University Press), 296-346.
Husain, M. (2008). "Hemispatial neglect," in Handbook of Clinical Neurology, eds G. Goldenberg and B. L. Miller (Amsterdam: Elsevier), 359-372.

Jacquin-Courtois, S., Rode, G., Pavani, F., O'Shea, J., Giard, M. H., Boisson, D., and Rossetti, Y. (2010). Effect of prism adaptation on left dichotic listening deficit in neglect patients: glasses to hear better? Brain 133, 895-908.

Jeannerod, M., and Biguer, B. (1987). "The directional coding of reaching movements. A visuomotor conception of spatial neglect," in $\mathrm{Neu}$ rophysiological and Neuropsychological Aspects of Spatial Neglect, ed. M. Jeannerod (Amsterdam: Elsevier), 87-113.

Karnath, H. O. (1994). Subjective body orientation in neglect and the interactive contribution of neck muscle proprioception and vestibular stimulation. Brain 117, 1001-1012.

Karnath, H. O. (1997). Spatial orientation and the representation of space with parietal lobe lesions. Philos. Trans. R. Soc. Lond., B, Biol. Sci. 352, 1411-1419.

Karnath, H. O., Baier, B., and Nagele, T. (2005). Awareness of the functioning of one's own limbs mediated by the insular cortex? J. Neurosci. 25, 7134-7138.

Karnath, H. O., and Rorden, C. (2012). The anatomy of spatial neglect. $\mathrm{Neu}$ ropsychologia 50, 1010-1017.

Luauté, J., Michel, C., Rode, G., Pisella, L., Jacquin-Courtois, S., Costes, N., Cotton, F., Le Bars, D., Boisson, D., Halligan, P., and Rossetti, Y. (2006). Functional anatomy of the therapeutic effects of prism adaptation on left neglect. Neurology 66, 1859-1867.

Makin, T. R., Holmes, N. P., and Zohary, E. (2007). Is that near my hand? Multisensory representation of peripersonal space in human intraparietal sulcus. J. Neurosci. 27, 731-740.

Mancini, F., Bricolo, E., Mattioli, F. C., and Vallar, G. (2011). Visuohaptic interactions in unilateral spatial neglect: the cross modal Judd illusion. Front. Psychol. 2:341. doi:10.3389/fpsyg.2011.00341

Maravita, A. (2006). From "body in the brain" to "body in space": sensory and intentional components of body representation, in Human Body Perception from the Inside Out, eds I. M. Thornton, M. Grosjean, and M. Shiffrar (New York: Oxford University Press), 65-88.

Maravita, A., Mcneil, J., Malhotra, P., Greenwood, R., Husain, M., and Driver, J. (2003a). Prism adaptation can improve contralesional tactile perception in neglect. Neurology 60, 1829-1831.

Maravita, A., Spence, C., and Driver, J. (2003b). Multisensory integration and the body schema: close to hand and within reach. Curr. Biol. 13, R531-R539.

McIntosh, R. D., Rossetti, Y., and Milner, A. D. (2002). Prism adaptation improves chronic visual and haptic neglect: a single case study. Cortex 38, 309-320.

Michel, C., Rossetti, Y., Rode, G., and Tilikete, C. (2003). After-effects of visuo-manual adaptation to prisms on body posture in normal subjects. Exp. Brain Res. 148, 219-226.

Moro, V., Urgesi, C., Pernigo, S., Lanteri, P., Pazzaglia, M., and Aglioti, S. M. (2008). The neural basis of body form and body action agnosia. $\mathrm{Neu}$ ron $60,235-246$.

Nys, G. M., De Haan, E. H., Kunneman, A., De Kort, P. L., and Dijkerman, H. C. (2008). Acute neglect rehabilitation using repetitive prism adaptation: a randomized placebocontrolled trial. Restor. Neurol. Neurosci. 26, 1-12.

Petkova, V. I., Bjornsdotter, M., Gentile, G., Jonsson, T., Li, T. Q., and Ehrsson, H. H. (2011). From part- to wholebody ownership in the multisensory brain. Curr. Biol. 21, 1118-1122.

Pisella, L., Rode, G., Farnè, A., Boisson, D., and Rossetti, Y. (2002). Dissociated long lasting improvements of straight-ahead pointing and line bisection tasks in two hemineglect patients. Neuropsychologia 40, 327-334.

Pizzamiglio, L., Antonucci, G., Judica, A., Montenero, P., Razzano, C., and Zoccolotti, P. (1992). Cognitive rehabilitation of the hemineglect disorder in chronic patients with unilateral right brain damage. J. Clin. Exp. Neuropsychol. 14, 901-923.

Preston, C., and Newport, R. (2011). Evidence for dissociable representations for body image and body schema from a patient with visual neglect. Neurocase 17, 473-479.

Redding, G. M., Rossetti, Y., and Wallace, B. (2005). Applications of prism adaptation: a tutorial in theory and method. Neurosci. Biobehav. Rev. 29, 431-444.

Rizzolatti, G., Fadiga, L., Fogassi, L., and Gallese, V. (1997). The space around us. Science 277, 190-191.

Rode, G., Klos, T., Courtois-Jacquin, S., Rossetti, Y., and Pisella, L. (2006a). Neglect and prism adaptation: a new therapeutic tool for spatial cognition disorders. Restor. Neurol. Neurosci. 24, 347-356.

Rode, G., Michel, C., Rossetti, Y., Boisson, D., and Vallar, G. (2006b). Left size distortion (hyperschematia) after right brain damage. $\mathrm{Neu}$ rology 67, 1801-1808.

Rode, G., and Perenin, M. T. (1994). Temporary remission of representational hemineglect through vestibular stimulation. Neuroreport 5, 869-872.

Rorden, C., and Brett, M. (2000). Stereotaxic display of brain lesions. Behav. Neurol. 12, 191-200.

Rossetti, Y., Jacquin-Courtois, S., Rode, G., Ota, H., Michel, C., and Boisson, D. (2004). Does action make the link between number and space representation? Visuo-manual adaptation improves number bisection in unilateral neglect. Psychol. Sci. 15, 426-430.

Rossetti, Y., Rode, G., Pisella, L., Farnè, A., Li, L., and Boisson, D. (1999). "Sensori-motor plasticity and cognition: prism adaptation can affect various levels of space representation," in Studies in Perception and Action, eds M. Grealy and J. A. Thomson (New York: Erlbaum), 265-269.

Rossetti, Y., Rode, G., Pisella, L., Farnè, A., Li, L., Boisson, D., and Perenin, M. T. (1998). Prism adaptation to a rightward optical deviation rehabilitates left hemispatial neglect. Nature 395, 166-169.

Sarri, M., Greenwood, R., Kalra, L., Papps, B., Husain, M., and Driver J. (2008). Prism adaptation aftereffects in stroke patients with spatial neglect: pathological effects on subjective straight ahead but not visual open-loop pointing. Neuropsychologia 46, 1069-1080.

Schenkenberg, T., Bradford, D. C., and Ajax, E. T. (1980). Line bisection and unilateral visual neglect in patients with neurologic impairment. $\mathrm{Neu}$ rology 30, 509-517.

Sirigu, A., Grafman, J., Bressler, K., and Sunderland, T. (1991). Multiple representations contribute to body knowledge processing. Evidence from a case of autotopagnosia. Brain 114, 629-642.

Sposito, A. V., Bolognini, N., Vallar, G., Posteraro, L., and Maravita, A. (2010). The spatial encoding of body parts in patients with neglect and neurologically unimpaired participants. Neuropsychologia 48, 334-340.

Vallar, G. (1998). Spatial hemineglect in humans. Trends Cogn. Sci. (Regul. Ed.) 2, 87-97. 
Vallar, G., Antonucci, G., Guariglia, C., and Pizzamiglio, L. (1993). Deficits of position sense, unilateral neglect and optokinetic stimulation. $\mathrm{Neu}$ ropsychologia 31, 1191-1200.

Vallar, G., Burani, C., and Arduino, L. S. (2010). Neglect dyslexia: a review of the neuropsychological literature. Exp. Brain Res. 206, 219-235.

Vallar, G., Daini, R., and Antonucci, G. (2000). Processing of illusion of length in spatial hemineglect: a study of line bisection. Neuropsychologia 38, 1087-1097.

Vallar, G., and Maravita, A. (2009). "Personal and extra-personal spatial perception," in Handbook of Neuroscience for the Behavioral Sciences, eds G. C. Berntson and J. T. Cacioppo (New York: John Wiley \& Sons), 322-336.
Vallar, G., and Papagno, C. (2003). Pierre Bonnier's (1905) cases of bodily "aschématie", in Classic Cases in Neuropsychology, eds C. Code, C. W. Wallesch, Y. Joanette and A. R. Lecours (Hove, East Sussex: Psychology Press), 147-170.

Vallar, G., and Rode, G. (2009). Commentary on Bonnier P. L'aschématie. Rev Neurol (Paris) 1905;13:605-9. Epilepsy Behav. 16, 397-400.

Vallar, G., and Ronchi, R. (2009). Somatoparaphrenia: a body delusion. A review of the neuropsychological literature. Exp. Brain Res. 192, 533-551.

Vallar, G., Rusconi, M., Fontana, S., and Musicco, M. (1994). Tre test di esplorazione visuo-spaziale: Taratura su 212 soggetti normali. Arch. Psicol. Neurol. Psichiatr. 55, 827-841.
Vallar, G., Zilli, T., Gandola, M. and Bottini, G. (2006). Productive and defective impairments in the neglect syndrome: graphic perseveration, drawing productions and optic prism exposure. Cortex 42, 911-920.

Vallar, G., and Bolognini, N. (in press). "Unilateral spatial neglect," in The Oxford Handbook of Attention, eds A. C. Nobre and S. Kastner (Oxford: Oxford University Press).

Wilson, B., Cockburn, J., and Halligan, P. W. (1987). Behavioural Inattention Test. Titchfield: Thames Valley Test.

Conflict of Interest Statement: The authors declare that the research was conducted in the absence of any commercial or financial relationships that could be construed as a potential conflict of interest.

Received: 27 January 2012; accepted: 16 May 2012; published online: 05 June 2012.

Citation: Bolognini N, Casanova D, Mar avita A and Vallar G (2012) Bisecting real and fake body parts: effects of prism adaptation after right brain damage. Front. Hum. Neurosci. 6:154. doi: 10.3389/fnhum.2012.00154

Copyright (C) 2012 Bolognini, Casanova, Maravita and Vallar. This is an openaccess article distributed under the terms of the Creative Commons Attribution Non Commercial License, which permits non-commercial use, distribution, and reproduction in other forums, provided the original authors and source are credited. 